IJRDM

50,13

Received 9 October 2020

Revised 6 November 2020

16 November 2020

15 March 2021

31 March 2021

14 July 2021

10 September 2021

4 October 2021

Accepted 17 November 2021

\section{Towards an increased understanding of learning: a case study of a collaborative relationship between a retailer and a logistics service provider}

\author{
Linnea Haag, Erik Sandberg and Uni Sallnäs \\ Department of Management and Engineering, Linköping University, \\ Linköping, Sweden
}

\begin{abstract}
Purpose - This study aims to explain how learning occurs in collaborative retailer-logistics service provider (LSP) relationships. The research is guided by two research questions, addressing absorptive and desorptive capacities and the interaction between these capacities.

Design/methodology/approach - The study is based on a case study of a Swedish, collaborative retailerLSP dyad. The empirical data are structured around five specific learning situations within the retailerLSP dyad.

Findings - The findings provide an explanation for how learning occurs within a collaborative retailer-LSP relationship based on subprocesses of absorptive and desorptive capacities. The interaction between these processes is found to rely on two types of support: one-directional and bidirectional. The findings also indicate positive outcomes of learning, such as improved cost efficiencies in warehouse operations, better customer services and improved long-term strategic planning.

Practical implications - This study shows how retailers and LSPs can learn from each other and together create an improved logistics system for end customers.

Originality/value - This research takes into account absorptive and desorptive capacities in a collaborative retailer-LSP relationship. This study enhances the understanding of inter-organisational learning processes in a retail logistics context.
\end{abstract}

Keywords Absorptive capacity, Desorptive capacity, Retailers, Logistics service providers, Organisational learning, Dyadic case study

Paper type Research paper

\section{Introduction}

As a result of ongoing mega trends such as digitalisation, e-commerce and omnichannel developments, the retail sector is currently undergoing major changes, in which logistics has been identified as a key source of competitive advantage (Hübner et al., 2016; Kembro and Norrman, 2019; Sorkun et al., 2020). For instance, effective and efficient material handling in the warehouse is a crucial component of logistics performance in an omnichannel environment (Kembro and Norrman, 2019), and for e-commerce, the timely and accurate distribution of ordered products is decisive for customer satisfaction (Xing et al., 2011).

(C) Linnea Haag, Erik Sandberg and Uni Sallnäs. Published by Emerald Publishing Limited. This article is published under the Creative Commons Attribution (CC BY 4.0) licence. Anyone may reproduce, distribute, translate and create derivative works of this article (for both commercial and non-commercial purposes), subject to full attribution to the original publication and authors. The full terms of this licence may be seen at http://creativecommons.org/licences/by/4.0/legalcode

Funding: The work was supported by the Hakon Swenson Foundation and Vinnova. Vinnova has the grant number: 2019-03197. 
Within this dynamic landscape, retail logistics activities are seldom conducted by retailers alone. Rather, behind the scenes, retailers outsource parts or all activities to logistics service providers (LSPs), which, in turn, delivers end-customer experiences (Perdana et al., 2019; Xing et al., 2011). With the increased reliance on LSPs, collaborative relationship between retailers and LSPs is vital to the success of retailing (Perdana et al., 2019; Sallnäs and Björklund, 2020; Shang, 2009). Such collaborative relationships are typically characterised by long-term expectations, high information sharing, joint problem-solving and the creation of win-win solutions (Halldórsson and Skjøtt-Larsen, 2004), in which resources are shared and combined to create a seamless customer experience.

A premise of this research is that a crucial ingredient in collaborative retailer-LSP relationships is the participants' ability to learn from each other (Panayides, 2007). Mutual learning plays a major role in the ability to continuously update and renew a joint resource base and sustain competitive advantage (Defee and Fugate, 2010). It has also been suggested to enhance the performance of logistics services within the supply chain (Halldórsson and SkjøttLarsen, 2004; Panayides, 2007). So far, however, research on organisational learning in retailerLSP collaborations has been geared towards quantitative research studies, indicating a positive relationship between organisational learning and supply chain performance. For instance, Shang (2009) concluded that there is a positive relationship between organisational learning among LSPs and financial supply chain performance. In a similar vein, Yang (2016) used structural equation modelling to confirm that there is a positive relationship between the logistics learning capability of international distribution centre operators and logistics service capability. In contrast, little is known about the actual learning processes that underscore organisational learning in retailer-LSP collaborations. Notably, Halldórsson and Skjøtt-Larsen (2004) touch upon the subject in their description of two learning processes between LSPs and their customers, but they do not go into detail about the mechanisms supporting such learning. Moreover, although organisational learning often emphasises the existence of mutual, interdependent learning processes across company borders, current research is often based on individual companies' learning processes, without taking into account interactions between companies (e.g. Panayides, 2007; Shang, 2009). Such "partner learning" is seldom empirically researched (Yang, 2016). To address these shortcomings, the overall aim of this study is to explain how learning occurs in collaborative retailer-LSP relationships.

This paper takes its stance in the theoretical lenses of absorptive and desorptive capacities (Lichtenthaler and Lichtenthaler, 2009; Ziegler, 2013), each comprising a set of subprocesses (elements) that together explain an organisation's ability to learn (absorptive capacity) and its ability to support learning at another organisation (desorptive capacity). Taken together, these two capacities provide an analytical tool for a comprehensive exploration of the organisational learning process, both within and between companies. To empirically explore these so far mainly theoretically derived capacities and how they interact, this paper builds on an empirical data set covering five detailed learning situations at a collaborative, Swedish retailer-LSP relationship. Our research is guided by two research questions:

$R Q 1$. How can the subprocesses of absorptive and desorptive capacity be described in a collaborative retailer-LSP relationship?

$R Q 2$. How can the interaction between absorptive and desorptive capacity be described in a collaborative retailer-LSP relationship?

The remainder of this paper starts by presenting the theoretical framework, including literature on learning in retailer-LSP collaborations and learning through absorptive and desorptive capacities. Thereafter, the methodology is presented, followed by the findings. The paper ends with a discussion and concluding remarks, including contributions and suggestions for future research.

An increased understanding of learning 
IJRDM

50,13

\section{Theoretical framework}

\subsection{The importance of learning in retailer-LSP collaborations}

Learning can be said to be vital in order for retailers and LSPs to identify, understand and use firm-specific competencies (e.g. expertise, learning) in order to jointly solve different challenges (Panayides, 2007). For example, as the demands of consumers increase, logistics performance needs to overcome challenges such as more flexible delivery options, shorter order response times, shorter delivery lead times, track and trace and easy ways to handle returns (Hübner et al., 2016; Kembro and Norrman, 2019). However, questions have been raised as to whether LSPs truly understand retailers sufficiently well to be able to deliver the logistics performance needed to satisfy consumers (Xing et al., 2011). At the heart of this issue, the importance of learning in retailer-LSP collaboration arises. Previous studies have, indeed, looked into this interface and acknowledged various aspects of learning. In a survey-based study of LSPs, for example, Panayides (2007) finds that intra-organisational learning by LSPs has a positive effect on both service effectiveness and firm performance. This is an important link, because the performance of LSPs has a direct impact on the performance of their customers and supply chains (see Panayides and So, 2005). Learning at the interface between LSPs and their customers was also examined by Halldórsson and Skjøtt-Larsen (2004). They separate between two closely related types of learning: learning from the other actor and joint learning. Learning from the other actor is exemplified by the development of a performance measurement system, by means of which the LSP gained valuable knowledge through close collaboration with the buying company. Joint learning is accomplished through joint projects in which both actors gain in skills and knowledge, exemplified by Halldórsson and Skjøtt-Larsen (2004) as a significant reduction in lead time as a consequence of the collaboration between an LSP and its customer. Adding to the studies on learning from an LSP perspective (Panayides, 2007; Panayides and So, 2005), Halldórsson and Skjøtt-Larsen (2004) thus highlighted the importance of inter-organisational learning for LSPs and their customers to be able to deliver superior supply chain performance. Further emphasising the importance of collaboration for learning, Panayides and So (2005) found that relational exchanges between LSPs and their customers have an effect on learning and, in turn, on supply chain performance.

\subsection{Learning through absorptive and desorptive capacities}

As our theoretical point of departure, we apply organisational learning (e.g. Cohen and Levinthal, 1990; Crossan et al., 1999; Hüber, 1991), which is considered a crucial foundation for a company's renewal and for sustaining competitive advantage (Crossan et al., 1999). As such, organisational learning is a vast, multidisciplinary research area that is addressed within research disciplines such as management, sociology and psychology. In logistics research, organisational learning often appears in connection with, or as an extension to, resource-based theories such as dynamic capabilities (Esper et al., 2007). It is often modelled in a variety of learning processes describing how knowledge is recognised, interpreted, articulated, formalised, shared and transformed - both internally and externally to the firm. To capture these processes, this research applies the theoretical concepts of absorptive and desorptive capacity, each of which is understood to contain a number of subprocesses.

Absorptive capacity has been defined by Zahra and George (2002, p. 186) as "a set of organizational routines and processes by which firms acquire, assimilate, transform, and exploit knowledge to produce a dynamic organizational capability". Thus, absorptive capacity includes four sequential subprocesses that together enable firms to identify, understand and use external knowledge (Zahra and George, 2002): 
(1) Acquisition: a firm's ability to identify and acquire external knowledge.

(2) Assimilation: a firm's routines and processes for analysing, processing, interpreting and understanding external knowledge.

(3) Transformation: a firm's ability to develop and refine routines that facilitate the combining of existing knowledge with acquired and assimilated knowledge.

(4) Exploitation: a firm's ability to refine, implement and leverage existing and new competencies based on acquired and transformed knowledge.

Grounded in dynamic capabilities theory, it is argued that a company's absorptive capacity is an essential ingredient in the creation and reconfiguring of the resources and capabilities necessary to build a sustainable competitive advantage (Meinlschmidt et al., 2016). Absorptive capacity has also been increasingly researched in logistics research, where it is recognised that external knowledge is a major source for various types of improvements, benefits and performance. For instance, Alkalha et al. (2019) demonstrated that a firm's absorptive capacity positively influences supply chain quality integration, and Saenz et al. (2014) demonstrated that absorptive capacity is positively related to innovation and performance in a buyer-seller context.

Expanding the perspective of organisational learning into an inter-organisational setting, which has been done in this research, the absorptive capacity of a knowledge-receiving organisation could be coupled with the desorptive capacity of a sender company (Meinlschmidt et al., 2016; Roldán Bravo et al., 2020). When enhancing supply chain competence, the absorptive capacity at the receiver organisation and the desorptive capacity at the sender organisation are complementary, vital dynamic capabilities (Roldán Bravo et al., 2020; Ziegler et al., 2013). Despite the potential for desorptive capacity to enhance supply chain performance, little research has been dedicated to the concept (Meinlschmidt et al., 2016; Ziegler et al., 2013). As outlined by Lichtenthaler and Lichtenthaler (2009), desorptive capacity is concerned with an organisation's ability to identify knowledge-transfer opportunities, as well as the effective transfer and application of knowledge at the receiving company (Lichtenthaler and Lichtenthaler, 2009; Roldán Bravo et al., 2020; Ziegler et al., 2013). More specifically, this ability can be divided into two sequential subprocesses (Lichtenthaler and Lichtenthaler, 2009):

(1) Identify knowledge-transfer opportunities: the ability to identify knowledge transfer opportunities.

(2) Transfer knowledge and facilitate application: the ability to transfer knowledge to the recipient.

This paper explores both absorptive and desorptive capacities and their subprocesses in order to study how learning occurs in a collaborative relationship between a retailer and an LSP.

\section{Methodology}

For this study, a single case study methodology (Dubois and Gadde, 2014; Dyer and Wilkins, 1991) was used in order to explain how learning occurs in a retailer-LSP relationship characterised by long-term collaboration and win-win thinking. The case was identified as one of several retailer-LSP dyads in a wider research project with the aim of studying dynamic capabilities in retailer-LSP interactions. For this particular retailer-LSP dyad, learning was found to be essential to the collaboration, and the researchers therefore chose to further explore this topic, aiming at detailed insights into the absorptive and desorptive capacities of retailers and LSPs and the interaction between these two constructs.
An increased understanding of learning 
IJRDM 50,13

\subsection{Case selection}

The studied retailer-LSP dyad is a "deep" case (Dyer and Wilkins, 1991) of a complex phenomenon, in which interdependent variables in complex structures can be illuminated (Dubois and Gadde, 2014). The case selection process, where the exact research questions have emerged based on empirical observations in a larger number of cases, is in line with Dubois and Gadde (2014), who suggest that sometimes "interesting empirical observations connect a researcher with a particular reality that provides opportunities for identification of exciting research phenomena" (p. 1,280). Short descriptions of the retailer, the LSP and the dyad are presented below.

The retailer is a large Swedish telecoms company that offers a large selection of telecoms services, including mobile, broadband and TV services, to businesses and private consumers in Northern Europe. At present, the retailer is focusing on integrating its own expertise in telecoms and logistics in order to develop its customer offerings and enhance the customer experience. For instance, last-mile deliveries and track and trace are highly prioritised by the retailer's logistics organisation.

The LSP is one of the leading LSPs in Northern Europe and offers a large selection of logistics solutions to both businesses and private consumers. It is thus a traditional LSP, as opposed, for example, to an e-fulfilment specialist, to use the terminology of Xing et al. (2011). The LSP is divided into a number of subsidiaries that operate in different countries. In this study, the Swedish subsidiary is studied due to its close collaboration with the retailer. This subsidiary includes several divisions that specialise in supply-chain-related operations, including logistics planning, warehousing and distribution. The LSP has a wide distribution network in Sweden and has extensive knowledge and experience regarding logistics.

The retailer-LSP dyad has been collaborating for over ten years. The LSP manages the majority of the retailer's logistics operations, including both warehousing and distribution, and the collaboration is explicitly structured at an agreement level, including fixed meetings at operational, tactical and strategic levels within both case companies. In recent years, the dyad has undertaken several logistics projects to jointly improve their logistics system, in which learning was essential to resolve different logistics issues (e.g. improvement of logistics operations, the development of a tracking device and development of a last-mile delivery solution).

\subsection{Data collection}

The data collection was conducted during 2019-2020 and included semi-structured interviews, observations and secondary data material. A total of ten semi-structured interviews were conducted, recorded and transcribed. Most of the interviews were performed face-to-face onsite and lasted between 30 and $120 \mathrm{~min}$. Some additional questions were answered by phone or email. This study encompassed a total of ten respondents, ranging from strategic logistics staff to business developers with a high degree of responsibility for the retailer-LSP collaboration. Key respondents were identified by asking the company contact (e.g. the logistics manager at the retailer), as well as participating in joint meetings between the retailer and the LSP. The fact that the respondents recommended each other as key respondents strengthened the study's reliability. A standardised interview guide was sent to the respondents prior to the interview, and it included questions based on the literature on shipper-provider relationships, as well as absorptive and desorptive capacities. The data collection ended when there was a theoretical saturation of data, which occurred when the marginal benefit of interviewing additional respondents became small (Saunders et al., 2018).

Additionally, three separate observations of joint meetings and workshops, each lasting four to six hours, were performed to study learning "in action". The observations took place onsite at the case companies and included joint tactical and operational meetings. 
The observations provided an additional element of learning within the dyad that might otherwise be difficult to capture. It also supported the identification of learning situations. Notes were taken during the observations to enable the researchers to go back to the material during the analysis phase.

In addition, secondary data, such as annual reports and presentation slides, were used. The annual reports provided a general understanding of the case companies, including business offers and sales markets. The presentation slides supported the identification of learning situations between retailers and LSPs, as the slides included descriptions of ongoing joint projects.

As a final step in the data collection, the data used in this paper were sent to the respondents to ensure that the information was correct, which strengthened the study's reliability (Yin, 2003).

\subsection{Data analysis}

The data analysis was based on five learning situations. These situations were identified by analysing the collected data and were chosen because they all included an extensive knowledge exchange between the retailer and the LSP, as well as requiring both parties to learn from each other's knowledge base (including firm-specific expertise, learnings and limitations) in order to jointly improve their logistics. These situations also had an important impact on their logistics performance related to e-commerce and omnichannel retailing. To further ensure the representativeness of the identified learning situations, they were verified by the logistics manager at the retailer, who was closely involved in the retailer-LSP collaboration.

The analysis of the empirical data was conducted in three steps. Firstly, the learning situations were studied individually and coded based on the six learning subprocesses of absorptive and desorptive capacities. For instance, to describe the acquisition process of the absorptive capacity, the definition of acquisition was used to create codes. In particular, acquisition was closely related to the identification and acquisition of external knowledge, for which codes like "identification" and "acquisition" as well as synonyms for these terms were used to code the collected data for each learning situation. The same coding logic was used for all subprocesses. This step resulted in the description of each learning situation.

In order to answer the first research question, the second step aimed to explain the processes of absorptive and desorptive capacities within the retailer-LSP collaboration. For this step, the characteristics of the subprocesses were compared using a pattern-matching technique (Yin, 2003), in order to explore similarities and differences between these processes in the learning situations. This resulted in a description of the six processes of the absorptive and desorptive capacities.

In the third step, the interaction between absorptive and desorptive capacities was studied in order to answer the second research question. In particular, the interaction between the processes of absorptive and desorptive capacities was first studied for each learning situation and later compared with the other situations in order to understand how the different processes interacted. This resulted in the identification of two interaction types.

\section{Findings}

In the following sections, the five identified learning situations are presented.

Learning situation A: The learning situation "Improvement in the LSP's packaging operations" was initiated by the retailer's operational logistics manager, who wanted to improve the LSP's existing packaging operations. Based on observations and interviews with operational logistics staff at the LSP, the retailer recognised internal logistics expertise that 
IJRDM 50,13 could be transferred in order to improve the LSP's packaging operations (identify knowledgetransfer opportunities). Based on this knowledge-transfer opportunity, the retailer shared logistics knowledge with the LSP at a series of joint tactical meetings and field visits (transfer knowledge and facilitate application), during which the LSP's logistics staff acquired new logistics knowledge about how to improve packaging operations (acquisition). In particular, a new automated packaging machine was projected. Knowledge provided by the retailer was analysed internally at the LSP and further interpreted by asking the retailer follow-up questions about its logistics expertise and needs (assimilation). By answering the LSP's questions, the retailer transferred additional logistics knowledge (transfer knowledge and facilitate application). Based on the acquired and assimilated knowledge, the new automated packaging machine, and operations in conjunction with it, were tested in a joint pilot (transformation), in which the retailer provided feedback (transfer knowledge and facilitate application). Thereafter, the experiences and feedback from the test project were summarised, and the new packaging machine and related operations were refined and implemented at full scale at the LSP (exploitation). Overall, the main outcome of learning situation A was the implementation of a new, automated packaging machine and related processes, which, in turn, resulted in a variety of logistics performance improvements, in particular improved packaging accuracy and increased parcel volume efficiency.

Learning situation B: The learning situation "Improvement of the LSP's understanding of the retail sector" was initiated by the LSP, which wanted to better understand the logistical needs of its customers in the retail sector (including the retailer in this study). To do so, the LSP conducted interview studies with its largest retail shippers in order to acquire knowledge about similarities and differences in logistical needs between retail shippers (acquisition). The retailer discussed its logistical needs internally based on its specific retail sector (identify knowledge-transfer opportunities), and these were later transferred during the interviews with the LSP (transfer knowledge and facilitate application). The knowledge acquired from the interview studies was analysed by the LSP in order to interpret and summarise common logistical needs among its shippers (assimilation). The retailer complemented this with additional information when needed (transfer knowledge and facilitate application). Based on the acquired and assimilated knowledge, the LSP conducted an internal brainstorming session to develop new operational warehouse routines, of which some were subsequently tested in small-scale test projects (transformation). During the development, the retailer was in continuous dialogue with the LSP, by means of which new knowledge (e.g. feedback and expertise) was shared related to the new warehouse routines (transfer knowledge and facilitate application). Thereafter, the knowledge gained was used to further refine the routines and implement them at full scale (exploitation). The learning situation enabled the LSP to increase its knowledge about its customers' logistics needs and requirements, which, in turn, aided it in standardising its operational warehouse routines without jeopardising its services to different customers. This, in turn, provided opportunities for a reduction in unnecessary and inefficient practices, as well as improvements in economies of scale and scope in the warehouse operations.

Learning situation $C$ : The learning situation "Development of a tracking device" was initiated by the retailer, which identified an opportunity to share its expertise on tracking devices with the LSP at a joint, strategic innovative forum (identify knowledge-transfer opportunities). The LSP recognised the retailer's knowledge about tracking devices (acquisition), and the use of tracking devices in the LSP's distribution operations was discussed internally in order to further interpret the retailer's knowledge (assimilation). During this interpretation process, the retailer frequently shared knowledge (e.g. expertise and feedback) about tracking devices at operational, tactical and strategic meetings, in order to visualise how such a device could be used in their joint logistics system (transfer knowledge and facilitate application). In addition, the retailer also developed a real-time 
tracking device and assisted the LSP in testing it within its own distribution operations (transfer knowledge and facilitate application). The LSP tested the tracking device on the retailer's orders in a project (transformation), to which the retailer provided valuable input (transfer knowledge and facilitate application). Thereafter, the results of the project were evaluated and further refined by the LSP, and the tracking device was later implemented at full scale within the logistics system of the LSP for both the retailer and its other shippers (exploitation). This learning situation hence resulted in the implementation and full-scale use of a new tracking device. In particular, it resulted in an estimated $65 \%$ reduction in thefts and losses of the retailers' products during transportation within the Swedish market.

Learning situation D: The learning situation "Development of a new express-delivery solution" was initiated by the logistics manager of the retailer, who saw the need for an express-delivery solution (identify knowledge-transfer opportunities) that was later communicated to the LSP (transfer). The LSP acquired knowledge about the retailer's delivery needs at one of their joint tactical meetings (acquisition). The LSP analysed the retailer's delivery needs internally in a cross-functional team and asked the retailer follow-up questions in order to better understand its distribution needs (assimilation). In addition, the retailer shared knowledge about its operations and initiated a field visit to one of its retail stores in order for the LSP to observe the retailer's operations (transfer knowledge and facilitate application). This helped the LSP to better understand the retailer's operations and the capabilities required for a new delivery solution. Based on the acquired and assimilated knowledge, the LSP developed potential delivery solutions, which were later discussed and tested in a small-scale test project (transformation). In conjunction with this, the retailer provided additional feedback related to the express-delivery solutions (transfer knowledge and facilitate application). Thereafter, the LSP refined the new delivery solution and implemented it at full scale (exploitation). The result of learning situation D, that is, a new express-delivery solution provided to the retailer by the LSP, offers reduced lead times to end consumers, which is considered to be an increasingly important weapon for the retailer visà-vis its competitors on the Swedish market.

Learning situation $E$ : The learning situation "Resource sharing with other retail shippers employing the LSP" was initiated by the logistics manager at the retailer, who searched for potential resource sharing with the LSP's other retail shippers that had similar logistical needs. The LSP identified potential resource-sharing opportunities between the retailer and its other shippers (identify knowledge-transfer opportunities), which the retailer later acquired at a recurring tactical meeting (acquisition). The LSP presented a potential solution, in which the retailer and other shippers shared a warehouse that facilitated resource sharing between the retailer and another shipper (transfer knowledge and facilitate application). Thereafter, the retailer discussed this solution internally and asked the LSP follow-up questions in order to further understand various aspects (e.g. logistical needs) of the solution (assimilation). The retailer summarised the knowledge assimilated from the LSP internally in order to gain a complete picture of the suggested solution before making a final decision (transformation), in which the LSP transferred additional information when needed (transfer knowledge and facilitate application). Thereafter, the retailer decided to move forward with the solution suggested by the LSP, and later shared logistics resources with another shipper (exploitation). The major outcome of learning situation $\mathrm{E}$ has been increased opportunities for the LSP to enhance its economies of scale and scope, thanks to the resource sharing. The two retail shippers that are now served in the same warehouse by the LSP are in different sectors and have very different requirements, but together they offer increased volumes and a long-term planning horizon for the LSP, which is important, for instance, when considering new investments in warehouse equipment.
An increased understanding of learning 
IJRDM

50,13

\section{Discussion}

Based on the five learning situations, the subprocesses of absorptive and desorptive capacities and the interaction between the two capacities are discussed in the following sections.

\subsection{Absorptive capacity processes}

All four processes of an absorptive capacity were found within both the retailer and LSP. The first process of absorptive capacity, acquisition, was characterised by a span of activities including observations, field visits, interview studies and regular joint meetings (e.g. operational and tactical meetings and strategic innovative forums), in which new logistics knowledge was discovered and acquired. Such activities covered various logisticsrelated issues, ranging from operational to strategic. In particular, the findings showed that innovative forums were useful in order to identify external knowledge, as the retailer and LSP communicated their expertise and ideas for improvement more freely. In contrast to other relationships, the establishment of such joint activities (e.g. observations, interviews, joint meetings) that aim for a higher level of information sharing, is typically recognised among more collaborative relationships (such the studied relationship) (Halldórsson and SkjøttLarsen, 2004). The findings show that collaborative relationships have more joint activities that enable a higher level of acquisition.

Secondly, the assimilation process was characterised by activities including internal discussions and asking follow-up questions, in order to interpret the acquired knowledge. In particular, logistics staff discussed logistics knowledge internally, which resulted in the creation of follow-up questions that needed to be answered in order to fully interpret the external knowledge at hand (e.g. logistics expertise and needs). The habit of frequently asking questions between the retailer and the LSP appears to be crucial for understanding the partner's logistics knowledge in greater depth (e.g. logistics opportunities and limitations). Logistics systems are often complex, and retailers and LSPs do not by themselves have the necessary knowledge to fully understand different aspects of such systems. Therefore, assimilation is crucial in order for retailers and LSPs to interpret each other's expertise and build a joint understanding of the logistics system in order to improve it. The willingness to take time to interpret each other's expertise and establish a joint understanding of the logistics system is typically seen within collaborative relationships and can be explained by the long-term commitment and win-win thinking (as mentioned by Halldórsson and SkjøttLarsen, 2004). Based on this, assimilation is made to a higher extent among collaborative relationships than other relationships.

The third process, transformation, is characterised by the development and testing of new logistics solutions. The acquired and interpreted knowledge from the other party worked as a catalyst for changing the logistics system, whereby new logistics solutions were developed and tested in small-scale, joint test projects. In particular, joint test projects were a key activity in the majority of the learning situations (A, B, C, D) and were crucial for transforming the logistics system. These projects typically involved both parties, in which new solutions were developed by the retailer (A and C) and the LSP (B, D and E). Thereafter, the LSP tested the solutions in its operations and received continuous feedback from the retailer (A B, C, D). The learning situations showed that test projects were an important learning opportunity, in which both the retailer and the LSP tested various logistics solutions and identified aspects of the solutions that needed more refinement. The transformation process depends on frequent information sharing and joint solving of problems for the retailer and LSP, in order to successfully perform different test projects together. The findings also suggest that relationships with lower level of collaboration (e.g. arm's length relationships) that involves less information sharing and less joint problem-solving can have a harder time to successfully transform their resources into something valuable for the relationship. 
The final process of absorptive capacity, exploitation, was characterised by an evaluation of previous test projects, as well as implementation of new logistics solutions. The majority of learning situations (A, B, C, D) showed that some sort of refinement and implementation was made based on an evaluation of test projects performed during the transformative step. Based on the test projects performed, both the retailer and the LSP collected valuable experience and learning, which were then used to further refine new logistics solutions within the logistics system. As the LSP is the actor performing the logistics operations, it was usually the LSP that refined, implemented and exploited the new logistics solutions, while the retailer initiated, supported and exploited them. In learning situation E, however, the retailer was the one that actively processed and decided to implement a resource-sharing solution, and in this case the LSP was more of an enabler than an implementor. Similar to the transformation process, exploitation also depends on a high level of information sharing and joint problem-solving between the retailer and LSP. In other words, the findings suggest that collaborative relationships between retailers and LSPs support exploitation.

\subsection{Desorptive capacity processes}

The processes of the desorptive capacity were also found within the retailer and LSP. The first process, identify knowledge-transfer opportunities, was characterised by activities such as observations, interviews and joint meetings (e.g. operational and tactical meetings), which enabled logistics staff to recognise new knowledge-transfer opportunities. By actively participating in such activities, logistics staff from both parties frequently identified new opportunities to share knowledge. In particular, new opportunities arose when the retailer or the LSP requested specific external knowledge related to a particular learning situation (e.g. improved packaging operations or improved understanding of the retail sector). The establishment of joint activities between retailers and LSPs allows a high level of information sharing, which is typically found in collaborative relationships (Halldórsson and Skjøtt-Larsen, 2004). The findings suggest that collaborative relationships have more joint activities that can support the identification of knowledge-transfer opportunities. Without such activities, as for arm's length relationships, it can be harder to identify knowledgetransfer opportunities.

The second process, transfer knowledge and facilitate application, was characterised by activities such as interviews, field visits, joint meetings (e.g. operational, tactical and strategic meetings and joint workshops) and joint projects, which enabled logistics staff to transfer logistics knowledge. Such activities enabled the retailer and LSP to "mix and match" their expertise into new logistics solutions. In particular, knowledge was often transferred throughout a series of joint operational, tactical and strategic meetings and ongoing test projects, where questions related to external knowledge arose over time and triggered additional knowledge transfer between the retailer and LSP. The transfer process depends on frequent information sharing between the retailer and LSP in order to successfully transfer knowledge and implement new logistics solutions.

\subsection{Interaction between absorptive and desorptive capacities}

As often superficially indicated in the existing literature, the interaction between processes of absorptive and desorptive capacities is a recurring theme in the five learning situations. Figure 1 demonstrates how the interaction between absorptive and desorptive capacities in the setting of a retailer-LSP collaboration can occur.

The findings reveal two types of interaction, including one-directional support and bidirectional support. Considering these types of interaction, the five learning situations indicate three patterns for how the processes interact with each other. Firstly, the process of acquisition is supported in all five learning situations in a one-directional way by an 
IJRDM

50,13

54
Figure 1.

The interplay between the absorptive and desorptive capacities in the five learning situations

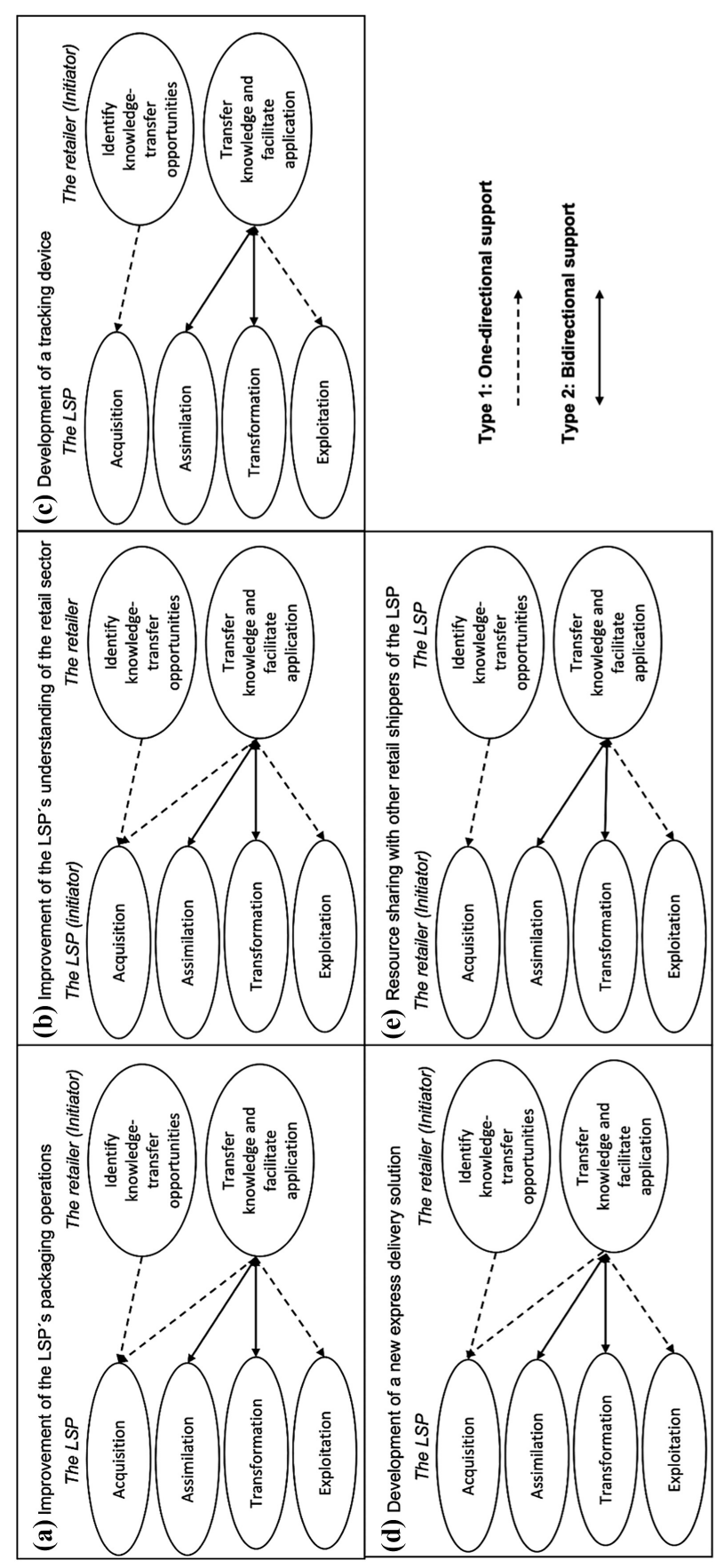


identifying process. In short, this means that knowledge is acquired more easily as a result of an identifying process at the knowledge-submitting company, but the acquisition process is not capable of strengthening this identifying process. A second pattern indicates that there is strong bidirectional support between the processes of assimilation and transformation at the knowledge-absorbing company on the one hand, and the transfer process at the knowledgesubmitting company on the other hand. In practice, the transformation process is often integrated and overlaps with the assimilation process at the absorbing company, and the transfer process at the submitting company hence supports them both, and vice versa. The interaction between these three processes (assimilation, transformation and transfer) is typically triggered when the knowledge-absorbing company begins to internally analyse the acquired external knowledge. Follow-up questions, meetings and other types of activities with the partner company mean that knowledge-transfer opportunities for the knowledgesubmitting company are enhanced. In a similar manner, during the subsequent transformation phase at the knowledge-absorbing company, the transfer process at the knowledge-submitting company continues to support the transformation at the absorbing company. A third, related observation indicates that the exploitation process at the knowledge-absorbing company was accelerated by one-directional support from the transfer process at the knowledge-submitting company in all five situations. In particular, knowledge transfer was crucial for the final refinement and implementation of new logistics solutions in the logistics system (learning situations A, C and D). Given the long-term collaboration between the retailer and LSP, the knowledge-submitting company has been able to follow the development of the knowledge-absorbing company and maintain a dialogue throughout both the transformation and the exploitation process.

Based on the findings, both structural and cultural factors of the collaborative relationship are suggested to impact upon the degree of interaction. In terms of structural factors, the retailer and LSP have jointly created a well-established infrastructure for their knowledge exchange. This includes a variety of formal and informal meetings, cross-functional teams and a network of knowledgeable staff. Altogether, this structure worked as a catalyst towards improved learning within retailer-LSP relationships. This is also in line with previous research (e.g. Esper et al., 2007; Panayides, 2007), which described a structural component as an important tool for organisational learning, including a formalised design of systems, processes and incentives. Furthermore, in line with existing research (Esper et al., 2007; Sinkula et al., 1997), cultural aspects such as open-mindedness, a shared logistics vision and commitment towards learning together reinforce the alignment of absorptive and desorptive capacity processes. In particular, the findings imply trust as an important prerequisite in order to exchange knowledge between retailers and LSPs. For instance, Esper et al. (2007) argued for the importance of trust in order to learn across organisational boundaries. Additionally, the observed patterns suggest that a long-term retailer-LSP relationship plays an essential role in the interaction between absorptive and desorptive capacities. A long-term relationship is built on trust and commitment on the part of both retailers and LSPs, and is therefore crucial for learning. Furthermore, these factors are also in line with the characteristics of collaborative relationships, which are characterised by long-term expectations, high information sharing, joint problem-solving and the creation of win-win solutions (Halldórsson and Skjøtt-Larsen, 2004).

\section{Concluding remarks}

This study has explained how learning occurs in a collaborative retailer-LSP relationship, guided by two research questions addressing absorptive and desorptive capacities and their interaction. Five specific learning situations have been outlined and described in terms of six learning subprocesses of absorptive and desorptive capacities. The interaction 
IJRDM 50,13

between these subprocesses has been analysed and was found to rely on two different types of support: one-directional and bidirectional support. The findings also indicated a variety of positive outcomes of the learning situations, including improved cost efficiencies in warehouse operations (e.g. enhanced economies of scale and scope, more efficient packaging operations), customer services (e.g. increased packaging accuracy and delivery lead times) and improved long-term, strategic planning with respect to aspects such as investments and collaboration.

These findings have several implications for research. Firstly, the qualitative case study has illustrated five learning situations that provide an in-depth exploration of the subprocesses that together explain an organisation's absorptive and desorptive capacities. The outcomes of each learning situation are also highlighted, hence empirically demonstrating the relevance and positive effects of joint learning in the context of a retailer-LSP collaboration. The paper thus complements the quantitative studies into retailer-LSP collaboration previously carried out (e.g. Shang, 2009; Yang, 2016; Panayides, 2007) by providing details about the specifics of how learning occurs. Secondly, previous research has mainly targeted a focal company's absorptive capacity (e.g. Knoppen et al., 2015; Saenz et al., 2014), without taking into account the desorptive capacity of the knowledgesubmitting company. In contrast, our wider perspective allows for a study on how absorptive and desorptive capacities interact across company borders. The findings presented here offer a systematic understanding of how collaborative organisational learning, outlined for instance as "partner learning" (Yang, 2016), works in practice, adding to the more general literature that addresses the collaborative performance of retailers and LSPs (e.g. Perdana et al., 2019; Tambo, 2014).

In terms of practical applications, this paper illustrates the strength of learning in retailer-LSP collaborations by providing examples of the benefits achieved in the five learning situations. Learning as such might not be a sufficient recommendation for retailers and LSPs, because it can only be planned or controlled to a certain extent (Tambo, 2014). However, the findings illustrate the importance of providing opportunities for learning situations to occur, through observations, field visits, regular and more specific joint meetings and so on. Without such joint efforts, the learning potential fades away, as interaction is needed to leverage absorptive and desorptive capacities. Furthermore, to establish such learning opportunities, long-term commitment appears essential. Thus, retailers who strive for enhanced logistics performance in their transition to e-commerce and omnichannel retailing should bear this in mind during the procurement of transport and logistics services, because they are often the decisive factor in terms of the length of relationships with LSPs.

In terms of future research, this paper has considered learning at an organisational level, ignoring the rich literature to be found at the group or individual level (e.g. Crossan et al., 1999). As a company's absorptive capacity could be considered a function of the absorptive capacities of its individual employees (Cohen and Levinthal, 1990; Meinlschmidt et al., 2016), a valuable next research step would be to extend the current research to lower organisational levels, or even to individuals. Another expansion of current research could focus on the inclusion of other parties, beyond the specific scope taken in this study. In particular, the customers of the retailer-LSP system, that is, the end consumers, could here provide further insights into the learning processes of the involved parties. Theoretical inspiration could be taken, for instance, from the concept of a logistics service triad (Childerhouse et al., 2013) and value co-creation in the service-dominant logic of the firm (Vargo and Lusch, 2004). For instance, the value co-creation processes and their relationship to both absorptive and desorptive capacities constitute an interesting avenue for future research. 


\section{References}

Alkalha, Z., Reid, I. and Dehe, B. (2019), "The role of absorptive capacity within supply chain quality integration”, Supply Chain Management: An International Journal, Vol. 24 No. 6, pp. 805-820.

Childerhouse, P., Luo, W., Basnet, C., Ahn, H.J., Lee, H. and Vossen, G. (2013), "Evolution of inter-firm relationships: a study of supplier-logistical services provider-customer traids", International Journal of Industrial Engineering, Vol. 20 Nos 1/2, pp. 126-140.

Cohen, W.M. and Levinthal, D.A. (1990), "Absorptive capacity: a new perspective on learning and innovation”, Administrative Science Quarterly, Vol. 35 No. 1, pp. 128-152.

Crossan, M.M., Lane, H.W. and White, R.E. (1999), "An organizational learning framework: from intuition to institution", Academy of Management Review, Vol. 24 No. 3, pp. 522-537.

Defee, C. and Fugate, B. (2010), "Changing perspective of capabilities in the dynamic supply chain era”, The International Journal of Logistics Management, Vol. 21 No. 2, pp. 180-206.

Dubois, A. and Gadde, L.-E. (2014), "Systematic combining - a decade later", Journal of Business Research, Vol. 67 No. 6, pp. 1277-1284.

Dyer, W.G. and Wilkins, A.L. (1991), "Better stories, not better constructs, to generate better theory: a rejoinder to Eisenhardt", Academy of Management Review, Vol. 16 No. 3, pp. 613-619.

Esper, T., Fugate, B. and Davis-Sramek, B. (2007), "Logistics learning capability: sustaining the competetive advantage gained through logistics leverage", Journal of Business Logistics, Vol. 28 No. 2, pp. 57-81.

Halldórsson, A. and Skjøtt-Larsen, T. (2004), "Developing logistics competencies through third party logistics relationships", International Journal of Operations and Production Management, Vol. 24 No. 2, pp. 192-206.

Hüber, G.P. (1991), "Organizational learning: the contributing processes and the literatures", Organization Science, Vol. 2 No. 1, pp. 88-115.

Hübner, A., Wollenburg, J. and Holzapfel, A. (2016), "Retail logistics in the transition from multichannel to omni-channel", International Journal of Physical Distribution and Logistics Management, Vol. 46 Nos 6/7, pp. 562-583.

Kembro, J. and Norrman, A. (2019), "Exploring trends, implications and challenges for logistics information systems in omni-channels", International Journal of Retail and Distribution Management, Vol. 47 No. 4, pp. 384-411.

Knoppen, D., Johnston, D. and Sáenz, M.J. (2015), "Supply chain relationships as a context for learning leading to innovation", The International Journal of Logistics Management, Vol. 26 No. 3, pp. 543-567.

Lichtenthaler, U. and Lichtenthaler, E. (2009), "A capability-based framework for open innovation: complementing absorptive capacity", Journal of Management Studies, Vol. 46 No. 8, pp. $1315-1338$.

Meinlschmidt, J., Foerstl, K. and Kirchoff, J.F. (2016), "The role of absorptive and desorptive capacity (ACDC) in sustainable supply management", International Journal of Physical Distribution and Logistics Management, Vol. 46 No. 2, pp. 177-211.

Panayides, P.M. (2007), "The impact of organizational learning on relationship orientation, logistics service effectiveness and performance", Industrial Marketing Management, Vol. 36 No. 1, pp. 68-80.

Panayides, P.M. and So, M. (2005), "Logistics service provider-client relationships", Transportation Research Part E: Logistics and Transportation Review, Vol. 41 No. 3, pp. 179-200.

Perdana, Y.R., Ciptono, W.S. and Setiawan, K. (2019), "Broad span of supply chain integration: theory development", International Journal of Retail and Distribution Management, Vol. 47 No. 2, pp. 186-201.

Roldán Bravo, M.I., Stevenson, M., Moreno, A.R. and Lloréns Montes, F.J. (2020), "Absorptive and desorptive capacity configurations in supply chains: an inverted U-shaped relationship", International Journal of Production Research, Vol. 58 No. 7, pp. 2036-2053.

An increased understanding of learning 
IJRDM 50,13

Saenz, M.J., Revilla, E. and Knoppen, D. (2014), “Absorptive capacity in buyer-supplier relationships: empirical evidence of its mediating role", Journal of Supply Chain Management, Vol. 50 No. 2, pp. 18-40.

Sallnäs, U. and Björklund, M. (2020), “Consumers' influence on the greening of distribution-exploring the communication between logistics service providers, e-tailers and consumers", International Journal of Retail and Distribution Management, Vol. 48 No. 11, pp. 1177-1193.

Saunders, B., Sim, J., Kingstone, T., Baker, S., Waterfield, J., Bartlam, B., Burroughs, H. and Jinks, C. (2018), "Saturation in qualitative research: exploring its conceptualization and operationalization”, Quality and Quantity, Vol. 52 No. 4, pp. 1893-1907.

Shang, K.-C. (2009), "Integration and organisational learning capabilities in third-party logistics providers", The Service Industries Journal, Vol. 29 No. 3, pp. 331-343.

Sinkula, J.M., Baker, W.E. and Noordewier, T. (1997), "A framework for market-based organizational learning: linking values, knowledge, and behavior", Journal of the Academy of Marketing Science, Vol. 25 No. 4, pp. 305-318.

Sorkun, M.F., Yumurtacı Hüseyinoğlu, I.Ö. and Börühan, G. (2020), "Omni-channel capability and customer satisfaction: mediating roles of flexibility and operational logistics service quality", International Journal of Retail and Distribution Management, Vol. 48, pp. 629-648.

Tambo, T. (2014), "Collaboration on technological innovation in Danish fashion chains: a network perspective", Journal of Retailing and Consumer Services, Vol. 21 No. 5, pp. 827-835.

Vargo, S.L. and Lusch, R.F. (2004), "Evolving to a new dominant logic for marketing”, Journal of Marketing, Vol. 68 No. 1, pp. 1-17.

Xing, Y., Grant, D.B., Mckinnon, A.C. and Fernie, J. (2011), "The interface between retailers and logistics service providers in the online market”, European Journal of Marketing, Vol. 45 No. 3 , pp. 334-357.

Yang, C.C. (2016), "Leveraging logistics learning capability to enable logistics service capabilities and performance for international distribution center operators in Taiwan", The International Journal of Logistics Management, Vol. 27 No. 2, pp. 284-308.

Yin, R.K. (2003), Case Study Research: Design and Methods, Sage Publications, Thousand Oaks.

Zahra, S.A. and George, G. (2002), "Absorptive capacity: a review, reconceptualization, and extension”, The Academy of Management Review, Vol. 27 No. 2, pp. 185-203.

Ziegler, N., Ruether, F., Bader, M.A. and Gassmann, O. (2013), "Creating value through external intellectual property commercialization: a desorptive capacity view", The Journal of Technology Transfer, Vol. 38 No. 6, pp. 930-949.

\section{Corresponding author}

Linnea Haag can be contacted at: linnea.haag@liu.se

For instructions on how to order reprints of this article, please visit our website:

www.emeraldgrouppublishing.com/licensing/reprints.htm

Or contact us for further details: permissions@emeraldinsight.com 